Article

\title{
Structural Relationships among Online Community Use, Parental Stress, Social Support, and Quality of Life between Korean and Taiwanese Employed Mothers
}

\author{
So Young Bae ${ }^{1}\left[\right.$, Po-Ju Chang ${ }^{2}$ and Choong-Ki Lee ${ }^{1, *(1)}$ \\ 1 College of Hotel \& Tourism Management, Kyung Hee University, 26 Kyungheedae-ro, Dongdaemun-gu, \\ Seoul 02447, Korea; sybae@khu.ac.kr \\ 2 Department of Horticulture and Landscape Architecture, National Taiwan University, No. 1, Section 4, \\ Roosevelt Rd, Taipei 10617, Taiwan; pojuchang@ntu.edu.tw \\ * Correspondence: cklee@khu.ac.kr
}

Received: 20 November 2020; Accepted: 15 December 2020; Published: 21 December 2020

\begin{abstract}
This study examined mothers' online community (OC) use and its structural relationship with parental stress, social support, and quality of life (QoL) under the social perspective of leisure and the theory of social support as a stress buffer. The population comprised employed mothers in two countries, Korea and Taiwan, which constitute appropriate settings for cross-cultural comparisons in the context of mothers' OC use. The online questionnaire was distributed to 12 Korean mothers' OCs and 14 Taiwanese mothers' OCs, targeting employed mothers who have at least one child under seven-years-old and access mothers' OCs on a regular basis. A total of 232 Korean and 303 Taiwanese responses were analyzed to examine the structural relationships among four key variables using structural equation modelling in AMOS 20. This study confirms that more parental stress leads to worse QoL. However, more parental stress results in less frequent participation in OCs, and OC use exerts a negative influence on QoL, which contradicts the hypothesized positive correlations. In comparison among Korean and Taiwanese mothers, Korean respondents showed a stronger influence of parental stress to mobilize more social support than did Taiwanese. This multidisciplinary study contributes to expanding the literature in noncommercial OCs, employed mothers in online leisure, and online social support in cross-cultural settings to promote the sustainability of families' wellbeing.
\end{abstract}

Keywords: online community; parental stress; social support; quality of life; employed mothers

\section{Introduction}

Women typically experience radical changes in their daily lives and intense stressors upon childbirth [1]. They often face a lack of social support and severe feelings of isolation under increased economic burdens and physical burnout [2,3]. Mothers who find it difficult to cope with stress frequently experience mental health problems. Extreme fatigue, sleep disorders, high-risk behaviors, and even suicide could follow maternal stress, which exert substantial negative impacts on mothers' quality of life (QoL) and children's development [4,5].

Such hardship is often more pronounced among employed mothers who play multiple roles in family and career life. According to a nationwide survey targeting Korean employed mothers, most respondents were under extreme distress [6], navigating their identity between being good mothers and ideal workers [7]. In addition, time constraints severely limit attempts by employed mothers to secure personal leisure time for reducing stress [8]. In Taiwan, the situation of employed mothers is similar to Korea. Taiwanese women usually spend 4.2 hours per day on housework, which is 
four times longer than the time spent by men [9]. Employed mothers with young children often end up working over the weekend unlike men [10], which could strongly affect their leisure participation.

Social support has been considered one of the major stress coping strategies [11,12]. Cohen and Wills [11] offered a theoretical model of social support as a stress buffer, which argues that social support decreases the level of stress and, in turn, produces a positive influence on QoL. Since internet use became widespread globally in the early 1990s, social support has been pursued in the online space, where individuals are connected to one another beyond temporal, spatial, and geographical barriers [2,13]. Online communities (OCs) have not only served an essential role to promote businesses [14], but have also become a space to enjoy social leisure, particularly for mothers to overcome social isolation and exchange social support based on a strong sense of companionship $[15,16]$. OCs used as a leisure activity could enable mothers to minimize their daily stress, reduce depressive feelings, experience positive energy, and enrich life meanings [17].

The purpose of this study is to highlight mothers' OC use and its structural relationships with parental stress, social support, and QoL under the social perspective of leisure [18] and the theory of social support as a stress buffer [11]. In particular, the population of this study includes employed mothers in two countries, Korea and Taiwan, which provide an appropriate setting for a cross-cultural comparison in the context of mothers' OC use: (1) Both countries share similar socio-cultural backgrounds based on comparable patterns of economic growth [19]; (2) each government has been heavily interested in women's childcare and economic participation [19]; and (3) Koreans and Taiwanese exhibit extremely frequent access to the Internet [20,21].

\section{Literature Review}

\subsection{Parental Stress and Social Support}

Stress is a response to stressors that cause behavioral readjustment in social, internal, and environmental aspects [22]. In the process of childbirth and childcare, parents experience a variety of stressors such as economic burdens, physical tiredness, and leisure constraints [1]. The ideology of intensive mothering (i.e., good mothers should sacrifice for their children) often intensifies the strain on mothers by imposing a sense of isolation, guilt, and pressure in an "anxiety-inducing culture of motherhood" [16,23] (p. 62). In particular, working mothers are frequently frustrated in balancing two seemingly contradictory tasks of childbearing and career, resulting in psychological disorders and physical illnesses, as well as producing disruptive behaviors in children [24]. Such stress becomes intensified under the high level of uncertainty and subsequent perceived risks such as COVID-19 [25-27].

According to Cohen and Wills [11], social support buffers stress and improves QoL. Social support is a strong predictor of physical and mental health, which results in increased well-being [28]. Individuals seek psychological, instrumental, informative, and appraisal support from their family, friends, and colleagues to cope with tensions from stressors [22,29]. When experiencing a stressful event, an individual who perceives more social support is likely to cope with possible damage and appraise the situation as not being so stressful. Researchers have also examined the effect of social support to reduce the level of psychological hardship such as depression or mental fatigue, and thus, ultimately contribute to individuals' well-being [30,31].

People exchange a great deal of social support through online support groups based on shared interests and experiences [13]. Anonymity allows people to feel more "egalitarian" and comfortable sharing sensitive issues with those with whom they have relatively weak social bonds because physical, social, and demographic cues are hidden in cyberspace [32,33] ([13], p. 702). Thus, people expect to obtain emotional support from online social relationships and feel relieved from their own stressful problems, which increases their self-esteem [34].

Greater social support is extremely effective in reducing parental stress [35,36]. As parental stress is known to be repetitive and complicated, and could possibly threaten one's psychological and 
physical health, adequate social support is considered highly important [4,22]. However, researchers have mainly considered parental stress and social support among particular subgroups such as mothers, including parents with disabled children, pregnant women, and single mothers $[37,38]$. Despite the evident value of such research works, the remaining population of mothers who have experienced such acute life changes in the transition to motherhood also requires continuous and comprehensive investigation.

Parental stress has been discussed using various measurement scales that include parenting stress index (PSI) and parental stress scale (PSS). Abidin [24] first developed the PSI focusing on the three major domains of parental stress (i.e., parent characteristics, child characteristics, and life stress). Targeting different populations in various cultural or situational contexts, the reliability and validity have been tested and confirmed (e.g., [39-41]). Later, Berry and Johns [42] developed the PSS as a less clinically oriented measurement focusing on positive and negative aspects of parenting. Despite its usefulness, we used the PSI to measure parental stress in this study in order to understand wide-ranging aspects based on the characteristics of parents as well as children.

The concept of social support has been measured based on functional approaches and the structure of interpersonal relationships [43]. For example, social support survey from the medical outcomes study (MOS) includes emotional, informational, tangible, and affectionate social support highlighting its functions while the multidimensional scale of perceived social support (MSPSS) discusses the social support from different relationships such as significant other, family, and friends [43,44]. As the major source of social support in this study is limited to OC members, we instead focused on the functional aspect of OCs (i.e., informational and emotional) using an MOS scale.

To measure quality of life, we used Butler and Kern's [45] PERMA-Profiler, which includes five subdomains of flourishing (i.e., positive emotions, engagement, relationships, meaning, and accomplishment) based on Seligman's [46] well-being theory. Rather than using scales of life satisfaction or well-being (e.g., satisfaction with life scale (SWLS)), we attempted to examine the multidimensional aspects of quality of life in this study [45].

\subsection{Online Communities as Social Leisure}

Similar to traditional communities, OCs comprise individuals who are united based on a shared purpose, interest, and belief beyond the tangible limitations of time, place, and culture via a computer-mediated communication network [47,48]. Two major activities occur in an OC: (1) Posting one's opinions or knowledge; and (2) browsing information or opinions posted by other members. OCs function as "open collectives of dispersed individuals with members who are not necessarily known or identifiable and who share common interests" [49] (p. 1224).

Online spaces have facilitated convenient social leisure via mobile access anytime and anywhere [16]. These technologically mediated communities have offered a communication hub for individuals who suffer from social isolation and leisure constraints. For example, mothers often perceive more leisure constraints, particularly regarding outdoor activities due to the inherent uncertainty of time-use, in addition to intensive and unpredictable childcare needs [50]. However, online connections with peer mothers have become an essential part of their leisure activity [3]. While the use of online social media sometimes increases anxiety, depression, or fatigue because of repeated social comparison [51,52], mothers tend to be constantly connected to OCs and often form communities [16,53].

OCs are also considered a source of social support, which provide opportunities to their members to present themselves, build social connections, and exchange social support, which are less frequently achieved from physical neighborhoods $[2,3,47,54]$. In particular, individuals under severe hardship tend to rely on online social support when their existing social relationships become precarious [55]. In particular, the unprecedented COVID-19 pandemic has led individuals to spend more time in OCs and sustain their social network from online under extreme social distancing [56,57]. By participating in OCs, members feel a sense of belonging, exert influence on peer members, and experience a state of flow [58], therefore enhancing their well-being [59]. 
Computer-mediated communication and its influence on social change have been widely discussed (e.g., [60-63]). However, OCs have been relatively understudied while they necessitate separate academic attention rooted in their distinctive natures. First, previous research has mainly focused on brand communities as effective marketing tools (e.g., [14]). However, online communities based on individuals' shared interests with a noncommercial nature have received less attention despite its important role as a social leisure. Second, unlike Social Network Sites (SNS), which are based on personal networks with a significant overlap between "Facebook friends" and "real friends", many membership-based OCs offer communication opportunities for members in a relatively closed and anonymous setting. In particular, research on membership-based OCs from a leisure perspective has rarely been performed [64]. Thus, this study focuses on the use of membership-oriented, noncommercial OCs from the perspective of leisure, particularly among populations of working mothers.

\subsection{Cross-Cultural Research between Korea and Taiwan}

Cross-cultural researchers focus on a particular trait of interest and examine its causal relationship with other variables in the context of international or intercultural samples [65]. The present study aims to compare OC use among employed mothers in Korea and Taiwan based on the following reasons.

First, both countries share similar cultural and historical backgrounds as emerging developed countries in East Asia [19]. Both countries have experienced a comparable process of economic growth, primarily focusing on government-driven exports since achieving their independence [66]. The analogous historical contexts of these two countries have led researchers to perform a series of cross-cultural investigations on their economic growth, women's marriage and social participation, educational perspectives, tourism, and labor markets (e.g., [66-68]).

Second, both countries have exhibited different patterns in women's childcare and economic participation, while their cultural norms have similarly emphasized the importance of family based on Confucianism [19]. For instance, mothers have been considered the primary caregivers in Korea, but grandparents have occupied such roles in Taiwan [68]. In addition, the proportion of women aged 30 to 34 involved in economic activities was higher in Taiwan (76.7\%) than in Korea (54.4\%), although the number of working females has increased in both countries [68]. Considering socio-cultural differences regarding women's social roles and activities, this cross-cultural comparison would expand the understanding of women's lives and leisure in these two emerging East Asian countries.

Third, both countries constitute ideal settings to perform online research. Both countries are known for their intense and widespread use of online spaces. In Taiwan, the average daily length of mobile access is ranked first in the world at $197 \mathrm{~min}$ a day [21]. Moreover, approximately $85 \%$ of Korean people are Internet users, most of whom access the Internet on a daily basis [20]. Furthermore, OCs play an important role as special communities and sources of reliable support for mothers in both countries $[69,70]$. Thus, we selected Korea and Taiwan as our study context to compare mothers' OC use and its relationship with parental stress, social support, and QoL.

\subsection{Hypotheses and Research Model}

Extreme stress exerts negative influences on QoL $[4,11]$. Researchers have demonstrated this relationship and attempted to examine possible mediators to diminish the impact of stress on QoL (e.g., [71]). Caldwell and Smith [18] examined this issue from the social perspective of leisure. Stress acts as an inducer for leisure activities that reduce or eliminate stress [17,18], and ultimately contribute to improving QoL [18]. In line with extant literature, this study aims to consider OC use as a social leisure activity [16].

A consensus exists among researchers that OC participation results in enhanced QoL. For example, Wang et al. [72] reported that individuals who spend more time on SNS exhibited higher levels of well-being, supporting the "stimulation hypothesis", which asserts that personal well-being is stimulated by online communication [73]. In addition, previous findings indicate that people who are involved in more social activities report enhanced QoL [74]. Mahan et al. [74] demonstrated that 
frequent use of online communication contributes to social life satisfaction. Highlighting OC use as social leisure, this study posits the following hypotheses:

Hypothesis 1 (H1). Parental stress is positively associated with OC use.

Hypothesis 2 (H2). Parental stress is negatively associated with QoL.

Hypothesis 3 (H3). OC use is positively associated with QoL.

Social leisure participation is a major source of social support [75]. In societies in which people can access mobile devices at any time in their daily lives, individuals interact with others online and build social support [2,62]. Online spaces offer a "leisure-oriented social context" [16] (p. 52) that enables individuals to enjoy computer-mediated communication [2]. Furthermore, social support can be received from groups, as well as individuals [76]. This implies that people can pursue social support from OC activities. To examine the relationship between social support and OC use, this study posits the following hypothesis:

Hypothesis 4 (H4). OC use is positively associated with social support.

Social support constitutes an effective mediator between stress and QoL [77,78]. Boswell [77] and Lin et al. [78] claimed that stressful events trigger the "mobilization of social support" [79] (p. 688). Specifically, when an individual faces a life crisis, he or she is stimulated to mobilize networks to receive social support to deal with stressors, which in turn, promotes well-being [80]. Social support has been clearly demonstrated to be a significant predictor of QoL (e.g., [81]). In the context of the present study, social support plays a critical role in enhancing QoL among mothers (e.g., [82]). Therefore, this study posits the following hypotheses:

Hypothesis 5 (H5). Parental stress is positively associated with social support.

Hypothesis 6 (H6). Social support is positively associated with QoL.

There have been few studies demonstrating the relationships among OC use, parental stress, social support, and QoL in a comprehensive research model. Thus, this research attempted to fill this research gap by examining structural relationships among these four constructs. Based on the abovementioned literature, this study proposes a research model that includes the six hypotheses (Figure 1).

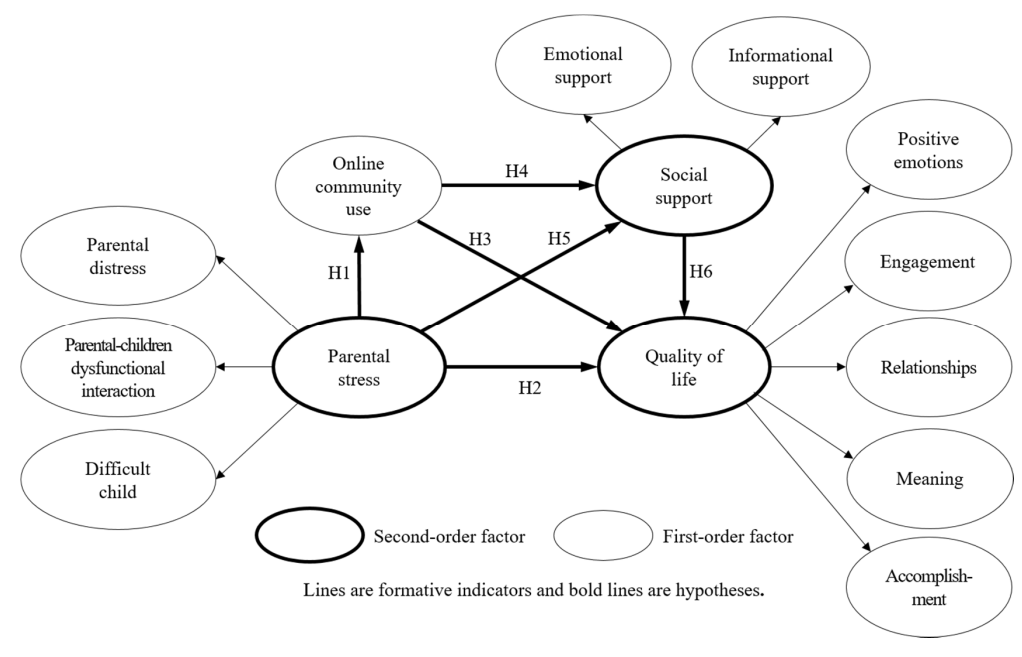

Figure 1. A proposed research model. 


\section{Methods}

\subsection{Measurements}

This study includes four main constructs: Parental stress, OC use, social support, and QoL. First, parental stress was measured using Abidin's [24] Parenting Stress Index (PSI) with three subscales: Parental distress (PD), parent-children dysfunctional interaction (PCDI), and difficult child (DC). To ensure the quality of the responses, a simplified PSI/Short-form (S-PSI/SF) was adapted using 15 items that comprise five for each subscale. Second, the intensity of OC use was assessed using three self-reported items: Frequency of visits per week, duration of each access, and duration of visits per week [83]. Third, social support was measured using eight items from Sherbourne and Stewart's [43] social support scale in a medical outcomes study (MOS). Of the four subscales, including emotional/informational support, tangible support, affectionate support, and positive social interaction, the items for emotional/informational support were utilized in this study because the other subscales were not applicable in the context of OCs. The eight-item online social support measurement was categorized into two types of social support, emotional support (ES) and informational support (IS), according to the exploratory factor analysis results. Fourth, QoL was assessed using the PERMA-Profiler, which Butler and Kern [45] developed based on the five dimensions of flourishing from Seligman's [46] PERMA model: Positive emotions (PE), engagement (EG), relationships (RL), meaning $(\mathrm{MN})$, and accomplishment (AC). The scale includes three items from each dimension, and higher scores indicate a higher state of well-being. Other than the three self-reported items to measure the intensity of OC use, all items were measured on a 5-point Likert scale (1: strongly agree; 5: strongly disagree).

To ensure content validity, two professionals each from Korea and Taiwan (i.e., who own a doctoral degree in leisure sciences and have conducted a series of research works in the area of leisure and quality of life) reviewed the appropriateness of the scales to each context. The questionnaire was developed in Korean and traditional Chinese languages, and reviewed by three individuals who are bilingual in Korean and Chinese to ensure compatibility. Then, the pilot survey was administered to 50 Korean and 30 Taiwan participants to verify the length and flow of the questionnaire, and revise ambiguous questions.

\subsection{Data Collection and Analysis}

The main survey was administered from 3 February to 20 March 2017 using convenience sampling. The population of this study includes women who: (1) Have at least one child under seven-years old; (2) are committed to paid employment; (3) access mothers' OC communities at least once a month; and (4) have citizenship in one research context (i.e., Korea or Taiwan). This study primarily targeted working mothers raising children under seven-years old because mothers perceive higher levels of stress from a newly imposed role as a parent, as well as a substantial amount of caregiving burdens [84,85]. The online questionnaire was developed using Qualtrics (www.qualtrics.com) and distributed to 12 Korean OCs and 14 Taiwanese OCs. All communities are not business-oriented, but formed voluntarily among members. In Korea, we recruited respondents from the most preferred platform for OCs called "cafe" operated by Korea's largest portal website, "Naver." In Taiwan, we recruited respondents from the websites focusing on the mother's life that provide OC platforms for their members.

A total of 232 Korean responses and 303 Taiwanese responses were used for the data analysis. Data were analyzed using structural equation modeling (SEM) in Amos 20 and multi-group analysis using z-scores. First, confirmatory factor analysis (CFA) was performed to test the factor structure of the scales and the fit of the measurement model. Then, the relationships among latent variables in the hypothesized research model (Figure 1) were tested using SEM. The model fit was evaluated with three goodness-of-fit indices: (1) The comparative fit index (CFI; [86]); (2) the Tucker-Lewis index (TLI; [87]); and (3) the root-mean-square error of approximation (RMSEA; [88]). CFI and TLI values of 0.90 or greater were considered highly acceptable and 0.80 or greater moderately acceptable [89-91]. 
RMSEA values of 0.08 or less indicated a good-fitting model [90]. Second, in comparing the difference between Korea and Taiwan, we conducted a multi-group invariance analysis using z-scores to test the potential moderating effect of country. The differences in z-score value between the constrained and the unconstrained model were calculated. We then compared each structural path in the Korean and Taiwanese models based on the z-score [92].

\section{Results}

\subsection{Profile of the Respondents}

As shown in Table 1, a majority of the respondents were between 30 and 39 years old, had university degrees, and had only one child. The monthly household income among Korean respondents showed a relatively even distribution in each category with 4 to 6 million KRW, and over 8 million KRW being slightly high. Most Taiwanese respondents earned from 70 to 90 thousand TWD. With reference to the population data, our samples had an average or higher education. In terms of income level, they could be categorized as middle class in each country.

Table 1. Demographic and general characteristics of respondents.

\begin{tabular}{|c|c|c|c|c|c|c|}
\hline \multirow[t]{2}{*}{ Characteristics } & \multicolumn{2}{|c|}{$\begin{array}{c}\text { Overall } \\
(n=535)\end{array}$} & \multicolumn{2}{|c|}{$\begin{array}{l}\text { Korean } \\
(n=232)\end{array}$} & \multicolumn{2}{|c|}{$\begin{array}{c}\text { Taiwanese } \\
(n=303)\end{array}$} \\
\hline & $\mathbf{n}$ & $\%$ & $\mathbf{n}$ & $\%$ & $\mathbf{n}$ & $\%$ \\
\hline \multicolumn{7}{|l|}{ Age (years) } \\
\hline Under 30 & 65 & 12.2 & 16 & 6.7 & 49 & 16.0 \\
\hline $30-39$ & 381 & 71.2 & 179 & 77.2 & 202 & 66.9 \\
\hline $40-49$ & 65 & 12.2 & 37 & 16.1 & 28 & 9.5 \\
\hline 50 or over & 24 & 4.5 & 0 & 0.0 & 24 & 7.6 \\
\hline \multicolumn{7}{|l|}{ Number of children } \\
\hline 1 & 292 & 54.6 & 114 & 49.2 & 178 & 58.3 \\
\hline 2 & 207 & 38.7 & 102 & 43.9 & 105 & 38.7 \\
\hline 3 or more & 36 & 6.7 & 16 & 6.9 & 20 & 6.7 \\
\hline \multicolumn{7}{|l|}{ Education } \\
\hline High school & 44 & 8.3 & 17 & 7.2 & 27 & 9.1 \\
\hline Two-year college & 90 & 16.8 & 37 & 16.0 & 53 & 17.4 \\
\hline University & 258 & 48.3 & 124 & 53.6 & 134 & 44.6 \\
\hline Graduate school & 143 & 26.6 & 54 & 23.2 & 89 & 29.0 \\
\hline \multicolumn{7}{|l|}{ Monthly household income } \\
\hline$<3 \mathrm{M} \mathrm{KRW} * /<30,000$ TWD ** & & & 28 & 11.9 & 8 & 2.5 \\
\hline 3-3.99 M KRW/30,000-49,999 TWD & & & 25 & 10.8 & 38 & 12.7 \\
\hline 4-4.99 M KRW/50,000-69,999 TWD & & & 37 & 16.0 & 68 & 22.5 \\
\hline 5-5.99 M KRW/70,000-89,999 TWD & & & 37 & 16.0 & 73 & 24.2 \\
\hline 6-6.99 M KRW/90,000-109,999 TWD & & & 33 & 14.4 & 44 & 14.5 \\
\hline 7-7.99 M KRW/110,000-129,999 TWD & & & 32 & 13.9 & 25 & 8.3 \\
\hline$>8 \mathrm{M} \mathrm{KRW} />130,000 \mathrm{TWD}$ & & & 40 & 17.0 & 47 & 15.2 \\
\hline
\end{tabular}

${ }^{*} \mathrm{M}$ KRW $=$ million Korean won, USD 1 = $1130 \mathrm{KRW} .{ }^{* *}$ USD 1 = 30.36 TWD (Taiwanese dollar).

\subsection{Measurement Model}

\subsubsection{Second-Order Analysis}

Second-order factor analysis is a useful method to interpret models with complex constructs that include more than one sublayer [93]. In this study, we considered three multi-layered latent constructs, parental stress, social support, and QoL, as second-order constructs and examined them using separate CFA. First, the second-order factor model for parental stress indicated a good fit to the data $\left(\chi^{2}[124, \mathrm{~N}=535]=425.04, p<0.001, \mathrm{CFI}=0.918, \mathrm{TLI}=0.880, \mathrm{RMSEA}=0.067\right)$. There were significant positive relationships between the three first-order factors (i.e., PD, PCDI, and DC) and the second-order factor along with the following factor loadings: 0.30 (PD), 0.69 (PCDI), and 0.82 (DC) 
$(p<0.001)$. The loading for PD was relatively low but still acceptable [94]. Considering the importance of all three first-order factors to constitute the construct of parental stress, we included PD for further analysis. Second, the second-order factor model for social support showed a good fit to the data $\left(\chi^{2}[17, \mathrm{~N}=535]=72.43, p<0.001, \mathrm{CFI}=0.973, \mathrm{TLI}=0.956, \mathrm{RMSEA}=0.078\right)$. There were significant positive relationships between the two first-order factors (i.e., IS and ES) and the second-order factor along with the following factor loadings: 0.89 (IS) and 0.79 (ES) $(p<0.001)$. Third, the second-order factor model for QoL demonstrated a good fit to the data $\left(\chi^{2}[82, \mathrm{~N}=535]=330.07, p<0.001\right.$, $\mathrm{CFI}=0.957, \mathrm{TLI}=0.945$, RMSEA $=0.075)$. There were significant positive relationships between the five first-order factors (i.e., PE, EG, RL, MN, and $\mathrm{AC}$ ) and the second-order factor along with the following factor loadings: 0.89 (PE), 0.95 (EG), $0.99(\mathrm{RL}), 0.88(\mathrm{MN})$, and $0.77(\mathrm{AC})(p<0.001)$. A series of second-order CFA results confirmed the multidimensionality of parental stress, social support, and QoL.

\subsubsection{First-Order Analysis}

Then, the first-order CFA was performed to assess the overall measurement model (Table 2). The measurement model test showed a good fit to the data $\left(\chi^{2}[48, \mathrm{~N}=535]=217,774, p<0.001\right.$, $\mathrm{CFI}=0.935, \mathrm{TLI}=0.895, \mathrm{RMSEA}=0.061$ ). The Cronbach's alpha values of all items were greater than 0.7 for reliability of internal consistency [95]. The composite reliability (CR) and average variance extracted (AVE) in the measurement model indicated the values greater than 0.7 and 0.5, respectively [96], demonstrating satisfactory construct reliability and convergent validity (Table 3 ). The square root of the AVE was greater than each correlation coefficient, which ensures discriminant validity [97]. In addition, the Heterotrait-Monotrait (HTMT) ratio is also included to examine the discriminant validity (Table 4). It is considered ideal when the values of the HTMT are equal to 1 [98]. In this study, discriminant validity was confirmed as the values of the HTMT were close to 1 (Table 4).

Table 2. Results of confirmatory factor analysis.

\begin{tabular}{|c|c|c|c|}
\hline Factors & Items & Factor Loading & Cronbach's $\alpha$ \\
\hline & Parental stress & & 0.866 \\
\hline \multirow{5}{*}{ PD } & I find myself giving up more to meet my children's needs & 0.716 & 0.836 \\
\hline & I feel trapped by my responsibilities as a parent & 0.686 & \\
\hline & I have been unable to do new and different things & 0.842 & \\
\hline & I feel that I am almost never able to do things that I like to do & 0.784 & \\
\hline & I don't enjoy things as I used to & 0.825 & \\
\hline \multirow{5}{*}{ PCDI } & Most times I feel that my child does not like me & 0.826 & 0.884 \\
\hline & My child smiles at me much less than I expected & 0.874 & \\
\hline & I get the feeling that my efforts are not appreciated very much & 0.581 & \\
\hline & When playing, my child doesn't often giggle or laugh & 0.892 & \\
\hline & My child doesn't seem to smile as much as most children & 0.898 & \\
\hline \multirow{5}{*}{$\mathrm{DC}$} & My child generally wakes up in a bad mood & 0.618 & 0.871 \\
\hline & I feel that my child is very moody and easily upset & 0.817 & \\
\hline & My child does a few things which bother me a great deal & 0.870 & \\
\hline & My child gets upset easily over the smallest things & 0.865 & \\
\hline & My child makes more demands on me than most children & 0.760 & \\
\hline \multirow{3}{*}{ OC use } & Average time spent on OC per each access & 0.972 & 0.728 \\
\hline & Average time spent on OC per week & 0.975 & \\
\hline & Number of visits to OC per week & 0.942 & \\
\hline \multicolumn{3}{|c|}{ Social support } & 0.884 \\
\hline \multirow{2}{*}{ IS } & I receive information to understand a certain situation via $\mathrm{OC}$ & 0.894 & 0.746 \\
\hline & I receive good advice about a crisis via OC & 0.800 & \\
\hline \multirow{6}{*}{ ES } & I can count on OC when I need to talk & 0.672 & 0.887 \\
\hline & I confide in others or talk about myself or my problems via OC & 0.787 & \\
\hline & OC is the channel that provides the advice I really want & 0.614 & \\
\hline & I share my most private worries and fears via OC & 0.873 & \\
\hline & I ask for suggestions to deal with a personal problem via OC & 0.777 & \\
\hline & I feel my problems are understood via OC & 0.780 & \\
\hline
\end{tabular}


Table 2. Cont.

\begin{tabular}{|c|c|c|c|}
\hline Factors & Items & Factor Loading & Cronbach's $\alpha$ \\
\hline & QoL & & 0.952 \\
\hline \multirow{3}{*}{$\mathrm{PE}$} & In general, I feel joyful in my current life & 0.789 & 0.874 \\
\hline & In general, I feel positive in my current life & 0.747 & \\
\hline & In general, I feel content in my current life & 0.803 & \\
\hline \multirow{3}{*}{ EG } & I become absorbed in what I am doing in my current life & 0.598 & 0.759 \\
\hline & I feel excited and interested in things in my current life & 0.761 & \\
\hline & I often lose track of time while doing what I enjoy currently & 0.867 & \\
\hline \multirow{3}{*}{ RL } & I receive help and support from others when I need it & 0.794 & 0.728 \\
\hline & I have been feeling loved in my current life & 0.584 & \\
\hline & I am satisfied with my personal relationships in my current life & 0.605 & \\
\hline \multirow{3}{*}{$\mathrm{MN}$} & I feel that I lead a purposeful and meaningful life currently & 0.604 & 0.903 \\
\hline & What I do in my life is valuable and worthwhile currently & 0.595 & \\
\hline & I feel that I have a sense of direction currently & 0.791 & \\
\hline \multirow{3}{*}{$\mathrm{AC}$} & I am making progress in accomplishing my goals currently & 0.854 & 0.843 \\
\hline & I often achieve the important goals I have set for myself & 0.812 & \\
\hline & I am often able to handle my responsibilities in my current life & 0.773 & \\
\hline
\end{tabular}

PD: Parental distress; PCDI: Parent-children dysfunctional interaction; DC: Difficult child; IS: Informational support; ES: Emotional support; PE: Positive emotions; EG: Engagement; RL: Relationships: MN: Meaning: AC: Accomplishment. Note: All boldfaced values for Cronbach's $\alpha$ are the reliability coefficients for each of the four latent constructs: Parental stress, OC use, social support, and QoL.

Table 3. Convergent validity.

\begin{tabular}{ccc}
\hline Construct & CR & AVE \\
\hline Parental stress & 0.909 & 0.506 \\
OC use & 0.715 & 0.500 \\
Social support & 0.889 & 0.504 \\
QoL & 0.928 & 0.566 \\
\hline
\end{tabular}

Note: CR: Composite reliability; AVE: Average variance extracted.

Table 4. Discriminant validity.

\begin{tabular}{ccccc}
\hline \multirow{2}{*}{ Construct } & \multicolumn{5}{c}{ Correlation of the Constructs } \\
\cline { 2 - 5 } & $\mathbf{1}$ & $\mathbf{2}$ & $\mathbf{3}$ & $\mathbf{4}$ \\
\hline Parental stress & $\mathbf{0 . 7 1 1}$ & 0.852 & 0.875 & 0.898 \\
OC use & -0.068 & $\mathbf{0 . 7 0 7}$ & 0.834 & 0.807 \\
Social support & $0.126^{* *}$ & $0.322^{* *}$ & $\mathbf{0 . 7 1 0}$ & 0.834 \\
QoL & $-0.382^{* *}$ & 0.008 & $0.103^{*}$ & $\mathbf{0 . 7 5 2}$ \\
\hline
\end{tabular}

${ }^{*} p<0.05,{ }^{* *} p<0.01$; Note: All boldfaced diagonal elements indicate the square roots of AVEs. Below the diagonal elements indicate the correlations between the construct values. Above the diagonal elements are the HTMT ratios.

\subsection{Structural Model}

After evaluating the measurement model, the structural model was examined for the research hypotheses. The final model (Figure 2) represented an acceptable fit to the data $\left(\chi^{2}[843, \mathrm{~N}=535]\right.$ $=2202.289, p<0.001, \mathrm{CFI}=0.892, \mathrm{TLI}=0.879, \mathrm{RMSEA}=0.055)$ (Table 5) $[89,91]$. The results of the hypotheses test are presented in Table 6. Parental stress indicated a significant negative influence on QoL $(\beta=-0.410, p<0.05)$, supporting H2 (Figure 2). However, the paths from parental stress to OC use and from OC use to QoL showed negative valence $(\beta=-0.129, p<0.05 ; \beta=-0.136, p<0.05)$ while being significant, rejecting $\mathrm{H} 1$ and H3. Meanwhile, parental stress showed a significant positive effect on social support $(\beta=0.144, p<0.05)$, which also positively influenced QoL $(\beta=0.205, p<0.05)$, supporting $\mathrm{H} 5$ and H6. Finally, OC use had a significant positive influence on social support $(\beta=0.420$, $p<0.05)$, supporting $\mathrm{H} 4$. 


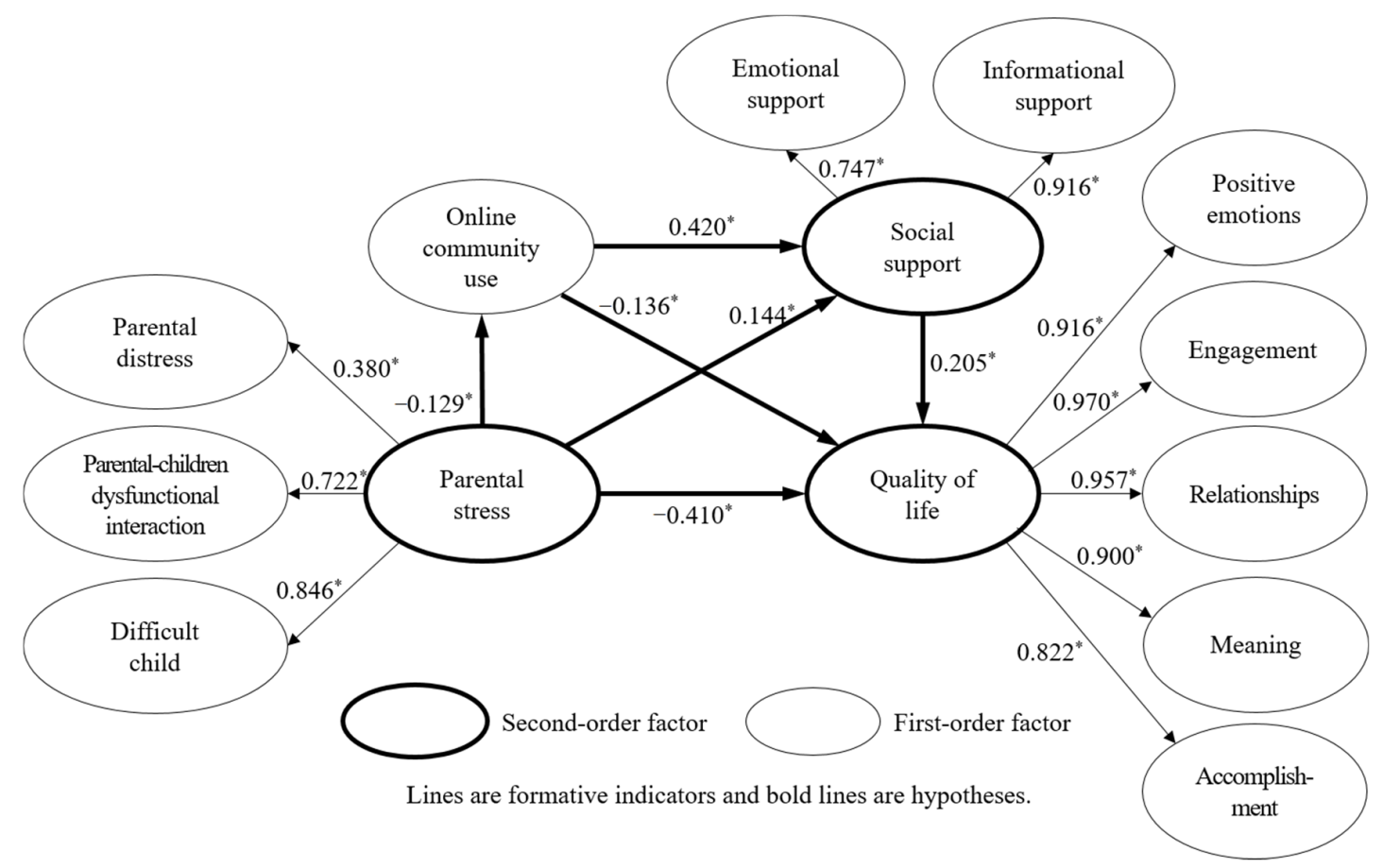

Figure 2. The final model. Note: Numbers indicate standardized structural estimates; controlling for respondents' age and the number of children; ${ }^{*} p<0.05$.

Table 5. Fit indices for measurement and structural models.

\begin{tabular}{cccc}
\hline Fit Indices & Recommended Value & Measurement Model & Structural Model \\
\hline Chi Square/df & $\leq 5.00$ & 4.536 & 2.612 \\
Comparative fit index (CFI) & $\geq 0.90$ & 0.935 & 0.892 \\
Tucker-Lewis index (TLI) & $\geq 0.90$ & 0.895 & 0.879 \\
Root-mean-square error of & $\leq 0.10$ & 0.061 & 0.055 \\
approximation (RMSEA) & & & \\
\hline
\end{tabular}

Table 6. Standardized structural estimates and tests of the hypotheses.

\begin{tabular}{cccc}
\hline Hypothesis & Path & Full Model Estimate & Test Results \\
\hline H1 & Parental stress $\rightarrow$ OC use & $-0.129^{*}$ & Rejected \\
H2 & Parental stress $\rightarrow$ QoL & $-0.410^{*}$ & Supported \\
H3 & OC use $\rightarrow$ QoL & $-0.136^{*}$ & Rejected \\
H4 & OC use $\rightarrow$ Social support & $0.420^{*}$ & Supported \\
H5 & Parental stress $\rightarrow$ Social support & $0.144^{*}$ & Supported \\
H6 & Social support $\rightarrow$ QoL & $0.205^{*}$ & Supported \\
\hline \multicolumn{4}{c}{$p<0.05}$.
\end{tabular}

In addition, parental stress was significantly influenced by the three first-order constructs, parental distress $(\beta=0.380, p<0.05)$, dysfunctional interaction $(\beta=0.722, p<0.05)$, and difficult child $(\beta=0.846, p<0.05)$. QoL was significantly predicted by the five first-order constructs, positive emotions $(\beta=0.916, p<0.05)$, engagement $(\beta=0.970, p<0.05)$, relationships $(\beta=0.957, p<0.05)$, meaning $(\beta=0.900, p<0.05)$, and accomplishment $(\beta=0.822, p<0.05)$. In addition, social support was significantly influenced by two first-order constructs, emotional support $(\beta=0.747, p<0.05)$ and informational support $(\beta=0.917, p<0.05)$.

\subsection{Multi-Group Comparison}

To examine the potential moderating effect of country, a multi-group analysis was conducted to compare differences in the coefficients of the corresponding structural paths for the Korean and 
Taiwanese model using z-score comparison to compare the means of these parameters for two groups [99]. The mean difference between two distributions and the standard error are needed to calculate the $\mathrm{z}$-score as $\mathrm{z}=$ mean difference/standard error. When the $|\mathrm{z}|$ is over 1.645 and the $p$-value is lower than 0.05 , there is a significant difference between two groups [100]. The results indicate that the path coefficients from parental stress to social support, social support to emotional support, and QoL to engagement were significantly different between Korean and Taiwanese (Table 7). More specifically, the effect from parental stress on social support and the effect from emotional support on social support among Koreans was much stronger than those among Taiwanese. The effects of engagement on QoL among Koreans were also stronger than those among Taiwanese.

Table 7. Results of comparisons of the path coefficients between Korean and Taiwanese employed mothers.

\begin{tabular}{cccccc}
\hline \multirow{2}{*}{ Path } & \multicolumn{2}{c}{ Korean } & \multicolumn{2}{c}{ Taiwanese } \\
\cline { 2 - 6 } & Estimate & $p$-Value & Estimate & $p$-Value & z-Score \\
\hline Parental stress $\rightarrow$ Social support & 0.504 & 0.015 & 0.009 & 0.000 & $-1.934^{*}$ \\
Emotional support $\rightarrow$ Social support & 1.043 & 0.000 & 0.661 & 0.000 & $-1.761^{*}$ \\
Engagement $\rightarrow$ QoL & 0.981 & 0.000 & 0.744 & 0.000 & $-2.494^{*}$ \\
Relationships $\rightarrow$ QoL & 0.687 & 0.000 & 0.398 & 0.000 & $-3.273^{*}$ \\
\hline
\end{tabular}

* $p<0.05$; Note: This table reports the unstandardized values for each group, which were used to calculate the z-scores suggested by Gaskin [92].

\section{Discussion and Implications}

This study examined OC use and its structural relationship with parental stress, social support, and QoL among employed mothers using the conceptual research model based on the social perspective of leisure [18] and the theory of social support as a stress buffer [11]. A cross-cultural comparison was also made between Korea and Taiwan. The key findings and implications are as follows.

First, the study confirms that more parental stress leads to worse QoL, which is consistent with previous findings $[4,11]$. However, social support moderates the relationship between parental stress and QoL. Specifically, severe parental stress facilitates more social support, which in turn, enhances QoL, supporting the extant literature [28]. This finding implies that Cohen and Wills' [11] theory of social support as a stress buffer works in the online context, as well. It seems that the power of weak ties is sufficiently strong for individuals to secure emotional and informational support online in the absence of geographic and temporal barriers [32,33]. Thus, it is plausible that many more unknown tertiary communities would be popularly accessed in the future by social support seekers in highly individualized and fragmented societies.

Second, the results indicate that more parental stress leads to less frequent participation in OC, which contradicts the hypothesized positive correlation between parental stress and OC use. In the social perspective of leisure, stress often motivates individuals to participate in more leisure activities, which ultimately enhances QoL $[16,17]$. The conflicting result of this study could be interpreted based on Cannon's [101] theory of fight or flight. Fight or flight refers to a prototype reaction from acute stress either to fight with or flee away from stress [101]. Employed mothers may choose not to stay longer in the mothers' OC, because these communities remind them of their anxiety produced from role conflict between intensive mothers and ideal workers [102,103]. In fact, OCs could be perceived as hostile and coercive because they often force mothers to be compliant to the norm and exacerbate psychological hardship on motherhood among mothers [104].

Third, this study demonstrates that OC use exerts a negative influence on QoL, which is opposed to the original hypothesis based on the role of OCs as online leisure that promotes one's QoL. Possible mediators in this relationship, such as negative emotions, may explain this conflicting result $[105,106]$. For example, while mothers' communities are considered helpful sources of social support and camaraderie to cope with parental stress, they could also be hostile to mothers by excluding 
some members and producing judgmental communications. Mothers also often feel overwhelmed by gendered ideologies that reinforce traditional gender roles (e.g., mothers being at home and fathers being at work) [106].

However, the addition of social support between OC use and QoL deserves attention. The results indicate that more OC use leads to a higher level of social support, which in turn, results in better QoL. Thus, it is reasonable to conclude that OCs are meaningful contributors to QoL only if individuals perceive a significant level of social support from OCs. According to Kahn and Antonucci's [107] convoy model of social relations, there is a wide-ranging set of factors that forms individuals' social networks. The findings of this study imply that what matters in OC use is not how much time members spend on them (i.e., quantity), but how intense their participation is to perceive or receive social support from them (i.e., quality).

Fourth, Korean respondents showed a stronger influence of parental stress to mobilize more social support than Taiwanese. According to Yang and Yen [68], childcare was considered the responsibility of mothers in Korea, while grandparents performed those duties in Taiwan. Compared to Taiwanese mothers, Korean mothers might feel a lack of social support with regards to physical surroundings in childcare, which increases their pursuit of social support under severe stress. In addition, considering that the factor loading of "relationships" constituting QoL was higher in the Korean model (0.687) than the Taiwanese model (0.398), it is plausible that Koreans place more emphasis on reliable relationships than Taiwanese to feel supported in hardship. While the effect of informational support on social support was stronger than emotional support in the overall model, the perceived influence of emotional support on social support was relatively higher among Koreans than Taiwanese. The finding may be associated with structural issues, such as a wide gender gap, that employed mothers experience at home, at work, and in society. In terms of workplace culture, for example, Korean employed mothers might tend to pursue more emotional support to compensate for their frustration at work with a lack of mother-friendly institutional support compared to that in Taiwan [108].

This study contributes to expanding the literature in noncommercial OCs, employed mothers in online leisure, and online social support in cross-cultural settings to promote the sustainability of families' wellbeing. First, it focused on nonbrand OCs not from the perspective of industry, but from the participants' viewpoint, which provides a unique lens to elucidate online leisure behaviors. Second, a meaningful contribution of the study is that an understudied population in leisure, employed mothers, was highlighted from a multidisciplinary perspective comprising leisure, communication, social psychology, and cyberspace. Third, this study applied Cohen and Wills' [11] model of social support as a stress buffer to the online context. Fourth, this cross-cultural research provided meaningful insight into different uses of OCs as online leisure.

This study offers the following practical implications. First, a company could encourage employed mothers to organize OCs in the workplace and provide institutional support to manage them. In addition, an anonymous online counselling service could be offered in OCs to support employed women to enhance their psychological well-being. Second, the government could give attention to employed mothers' QoL and administer a corresponding nation-wide survey on a regular basis. This survey would help officials to assess the needs of employed mothers in reality and develop various sources from which they could receive social support. In addition, it would increase the public's awareness of the inherent hardships faced by employed mothers, which in fact, could constitute another source of social support per se. Third, the results of this study could be utilized as a baseline result to develop a healthy leisure culture. They would also be applicable to other populations, such as office workers, younger adults, and older females who face day-to-day stress from their multiple role conflicts.

Despite its contributions, this study is not without its limitations. First, the choice of these two countries could be perceived as arbitrary, despite the value of the cross-cultural comparison between Korea and Taiwan. Comparisons among other cultural settings would be a significant contribution to OC research from the leisure perspective. Second, this study measured OC participation with frequency 
and duration of access, while types of participation were not considered. Examining participants' preferred activities would be useful to elucidate the difference in OC use among Korean and Taiwanese mothers. Third, the use of convenience sampling might have resulted in the underrepresentation of a particular subgroup such as lurkers who do not write but rather observe during their regular or irregular visit to OCs. A probability-based sampling approach would contribute to represent wide-ranging subgroups and ensure the generalizability of the findings. Fourth, this study included complete data only for analyses, which naturally excludes the dropouts. In the future, researchers would need to consider how to reduce potential bias in conducting an online survey. Lastly, this study was based on the cross-sectional data collection. Considering the significant impacts from the unprecedented COVID-19 pandemic, researchers would need to address the impact of individuals' perceived risks and subsequent behavioral changes from a longitudinal perspective.

Author Contributions: Conceptualization, S.Y.B., P.-J.C. and C.-K.L.; data curation, S.Y.B. and P.-J.C.; formal analysis, S.Y.B. and P.-J.C.; funding acquisition, S.Y.B.; writing-original draft, S.Y.B. and P.-J.C.; writing-review and editing, S.Y.B., P.-J.C. and C.-K.L. All authors have read and agreed to the published version of the manuscript.

Funding: This work was supported by the Ministry of Education of the Republic of Korea and the National Research Foundation of Korea (NRF-2016S1A5B5A01021635).

Conflicts of Interest: The authors declare no conflict of interest.

\section{References}

1. Crnic, K.A.; Greenberg, M.T. Minor parenting stresses with young children. Child. Dev. 1990, 61, 1628-1637. [CrossRef] [PubMed]

2. Drentea, P.; Moren-Cross, J.L. Social capital and social support on the web: The case of an internet mother site. Sociol. Health Illn. 2005, 27, 920-943. [CrossRef] [PubMed]

3. Parry, D.C.; Glover, T.D.; Mulcahy, C.M. From "stroller-stalker" to "momancer": Courting friends through a social networking site for mothers. J. Leis. Res. 2013, 45, 23-46. [CrossRef]

4. Lazarus, R.S. Coping theory and research: Past, present, and future. Psychosom. Med. 1993, 55, $234-247$. [CrossRef] [PubMed]

5. World Health Organization. Maternal Mental Health. Available online: http://www.who.int/mental_health/ maternal-child/maternal_mental_health/en/ (accessed on 3 February 2016).

6. Women \& Culture in Network. Working Mother Distress Index. Available online: http://www.networkwin. org/wp/?page_id=1913 (accessed on 3 February 2016).

7. Turner, P.K.; Norwood, K. Unbounded motherhood: Embodying a good working mother identity. Manag. Commun. Q. 2013, 27, 396-424. [CrossRef]

8. Brown, P.R.; Brown, W.J.; Miller, Y.D.; Hansen, V. Perceived constraints and social support for active leisure among mothers with young children. Leis. Sci. 2001, 23, 131-144. [CrossRef]

9. Directorate-General of Budget, Accounting and Statistics, Executive Yuan, Taiwan. The 2016 Report on Women's Marriages, Fertility, and Employment in Taiwan. Available online: https:/ebook.dgbas.gov.tw/ public/Data/771217174890V10W9I.pdf (accessed on 18 December 2019).

10. Lake, L.; Chin-fen, C. Gendering the job demands-resources model: Work-family conflict in Taiwan. Fam. Relatsh. Soc. 2020, 9, 431-450. [CrossRef]

11. Cohen, S.; Wills, T.A. Stress, social support, and the buffering hypothesis. Psychol. Bull. 1985, 98, 310-357. [CrossRef]

12. DeLongis, A.; Holtzman, S. Coping in context: The role of stress, social support, and personality in coping. J. Pers. 2005, 73, 1633-1656. [CrossRef]

13. White, M.; Dorman, S.M. Receiving social support online: Implications for health education. Health Educ. Res. 2001, 16, 693-707. [CrossRef]

14. Brodie, R.J.; Ilic, A.; Juric, B.; Hollebeek, L. Consumer engagement in a virtual brand community: An exploratory analysis. J. Bus. Res. 2013, 66, 105-114. [CrossRef]

15. Glover, T.D.; Parry, D.C. Friendships developed subsequent to a stressful life event: The interplay of leisure, social capital, and health. J. Leis. Res. 2008, 40, 208-230. [CrossRef] 
16. Valtchanov, B.L.; Parry, D.C.; Glover, T.D.; Mulcahy, C.M. 'A whole new world': Mothers' technologically mediated leisure. Leis. Sci. 2016, 38, 50-67. [CrossRef]

17. Adams, K.B.; Leibbrandt, S.; Moon, H. A critical review of the literature on social and leisure activity and wellbeing in later life. Ageing Soc. 2011, 31, 683-712. [CrossRef]

18. Caldwell, L.L.; Smith, E.A. Leisure: An overlooked component of health promotion. Can. J. Public Health 1988, 79, S44-S48.

19. Jung, E.H.; Kim, Y.M.; Kwon, H.J. Female employment in newly developed countries in East Asia: A comparison of Korea and Taiwan. J. Korean Women's Stud. 2012, 28, 147-181.

20. Korea Internet Security Agency. 2015 Annual report of the Internet use in Korea. Available online: http://www.kisa.or.kr (accessed on 10 February 2016).

21. Park, S.C. Taiwan, Top-Ranked in Smartphone Use: Presidential Nominees Communicate via 'Band'. Available online: http://biz.chosun.com/site/data/html_dir/2015/12/16/2015121600129.html (accessed on 10 February 2016).

22. Thoits, P.A. Social support and psychological well-being: Theoretical possibilities. In Social Support: Theory, Research and Applications; Springer: Dordrecht, The Netherlands, 1985; pp. 51-72.

23. Lloyd, B.; Hawe, P. Solutions forgone? How health professionals frame the problem of postnatal depression. Soc. Sci. Med. 2003, 57, 1783-1795. [CrossRef]

24. Abidin, R.R. Parenting Stress Index-Short Form; Pediatric Psychology Press: Atlanta, GA, USA, 1990.

25. Fontanesi, L.; Marchetti, D.; Mazza, C.; Di Giandomenico, S.; Roma, P.; Verrocchio, M.C. The effect of the COVID-19 lockdown on parents: A call to adopt urgent measures. Psychol. Trauma 2020, 12, S79-S81. [CrossRef]

26. Griffith, A.K. Parental burnout and child maltreatment during the COVID-19 pandemic. J. Fam. Violence 2020, 1-7. [CrossRef]

27. Russell, B.S.; Hutchison, M.; Tambling, R.; Tomkunas, A.J.; Horton, A.L. Initial challenges of caregiving during COVID-19: Caregiver burden, mental health, and the parent-child relationship. Child. Psychiat. Hum. Dev. 2020, 51, 671-682. [CrossRef]

28. Wong, S.T.; Wu, A.; Gregorich, S.; Pérez-Stable, E.J. What type of social support influences self-reported physical and mental health among older women? J. Aging Health 2014, 26, 663-678. [CrossRef] [PubMed]

29. House, J.S. Work Stress and Social Support; Addison-Wesley: Boston, MA, USA, 1981.

30. Nagy, E.; Moore, S.; Silveira, P.P.; Meaney, M.J.; Levitan, R.D.; Dubé, L. Low socioeconomic status, parental stress, depression, and the buffering role of network social capital in mothers. J. Ment. Health 2020, 1-8. [CrossRef] [PubMed]

31. Szkody, E.; Stearns, M.; Stanhope, L.; McKinney, C. Stress-Buffering Role of Social Support during COVID-19. Fam. Process 2020, 1-14. [CrossRef]

32. Coulson, N.S. Receiving social support online: An analysis of a computer-mediated support group for individuals living with irritable bowel syndrome. Cyberpsychol. Behav. 2005, 8, 580-584. [CrossRef]

33. Granovetter, M.S. The strength of weak ties. Am. J. Sociol. 1973, 78, 1360-1380. [CrossRef]

34. Eastin, M.S.; LaRose, R. Alt. support: Modeling social support online. Comput. Hum. Behav. 2005, 21, 977-992. [CrossRef]

35. Green, B.L.; Furrer, C.; McAllister, C. How do relationships support parenting? Effects of attachment style and social support on parenting behavior in an at-risk population. Am. J. Commun. Psychol. 2005, 40, 96-108. [CrossRef] [PubMed]

36. Liu, S.W.; Zhai, F.; Gao, Q. Parental stress and parenting in Chinese immigrant families: The mediating role of social support. Child. Fam. Soc. Work 2020, 25, 135-148. [CrossRef]

37. Aghaei, S.; Yousefi, Z. The effectiveness of quality of life therapy on psychological capitals and its dimensions among mothers of children with intellectual disability. Q. J. Child Ment. Health 2017, 4, 49-59.

38. Martin-West, S. The role of social support as a moderator of housing instability in single mother and two-parent households. Soc. Work. Res. 2019, 43, 31-42. [CrossRef]

39. Haskett, M.E.; Ahern, L.S.; Ward, C.S.; Allaire, J.C. Factor structure and validity of the parenting stress index-short form. J. Clin. Child. Adolesc. 2006, 35, 302-312. [CrossRef] [PubMed]

40. Reitman, D.; Currier, R.O.; Stickle, T.R. A critical evaluation of the Parenting Stress Index-Short Form (PSI-SF) in a head start population. J. Clin. Child. Adolesc. 2002, 31, 384-392. [CrossRef] [PubMed] 
41. Tam, K.K.; Chan, Y.C.; Wong, C.K.M. Validation of the parenting stress index among Chinese mothers in Hong Kong. J. Community Psychol. 1994, 22, 211-223. [CrossRef]

42. Berry, J.O.; Jones, W.H. The parental stress scale: Initial psychometric evidence. J. Soc. Pers. Relat. 1995, 12, 463-472. [CrossRef]

43. Sherbourne, C.D.; Stewart, A.L. The MOS social support survey. Soc. Sci. Med. 1991, 32, 705-714. [CrossRef]

44. Zimet, G.D.; Dahlem, N.W.; Zimet, S.G.; Farley, G.K. The multidimensional scale of perceived social support. J. Pers. Assess. 1988, 52, 30-41. [CrossRef]

45. Butler, J.; Kern, M.L. The PERMA-Profiler: A brief multidimensional measure of flourishing. Int. J. Well-Being 2016, 6, 1-48. [CrossRef]

46. Seligman, M. Flourish: A Visionary New Understanding of Happiness and Well-Being; Free Press: New York, NY, USA, 2011.

47. Lee, J.; Lee, H. The computer-mediated communication network: Exploring the linkage between the online community and social capital. New Media. Soc. 2010, 12, 711-727.

48. Rothaermel, F.T.; Sugiyama, S. Virtual internet communities and commercial success: Individual and community-level theory grounded in the atypical case of TimeZone.com. J. Manag. 2001, 27, $297-312$. [CrossRef]

49. Faraj, S.; Jarvenpaa, S.L.; Majchrzak, A. Knowledge collaboration in online communities. Organ. Sci. 2011, 22, 1224-1239. [CrossRef]

50. Hilbrecht, M.; Shaw, S.M.; Johnson, L.C.; Andrey, J. Remixing work, family and leisure: Teleworkers' experiences of everyday life. New Tech. Work. Employ. 2013, 28, 130-144. [CrossRef]

51. Dhir, A.; Yossatorn, Y.; Kaur, P.; Chen, S. Online social media fatigue and psychological wellbeing-A study of compulsive use, fear of missing out, fatigue, anxiety and depression. Int. J. Inform. Manag. 2018, 40, 141-152. [CrossRef]

52. Lup, K.; Trub, L.; Rosenthal, L. Instagram\# instasad: Exploring associations among instagram use, depressive symptoms, negative social comparison, and strangers followed. Cyberpsychol. Behav. Soc. Netw. 2015, 18, 247-252. [PubMed]

53. Turner, V. The Ritual Process: Structure and Anti-Structure; Routledge: London, UK, 1969.

54. Bîră, M.; Buzoianu, C.; Tudorie, G. Social Support Mediated by Technology. A Netnographic Study of an Online Community for Mothers. Rom. J. Commun. Public Relat. 2020, 22, 57-71. [CrossRef]

55. Classen, C.; Koopman, C.; Angell, K.; Spiegel, D. Coping styles associated with psychological adjustment to advanced breast cancer. Health Psychol. 1996, 15, 434-437. [CrossRef]

56. Jang, I.C.; Choi, L.J. Staying connected during COVID-19: The social and communicative role of an ethnic online community of Chinese international students in South Korea. Multilingua 2020, 39, 541-552. [CrossRef]

57. Chen, I.S. Turning home boredom during the outbreak of COVID-19 into thriving at home and career self-management: The role of online leisure crafting. Int. J. Contemp. Hosp. 2020, 32, 3645-3663. [CrossRef]

58. Koh, J.; Kim, Y.G.; Kim, Y.G. Sense of virtual community: A conceptual framework and empirical validation. Int. J. Electron. Commer. 2003, 8, 75-94. [CrossRef]

59. Eysenbach, G.; Powell, J.; Englesakis, M.; Rizo, C.; Stern, A. Health related virtual communities and electronic support groups: Systematic review of the effects of online peer to peer interactions. BMJ 2004, 328, 1166. [CrossRef]

60. Back, M.D.; Stopfer, J.M.; Vazire, S.; Gaddis, S.; Schmukle, S.C.; Egloff, B.; Gosling, S.D. Facebook profiles reflect actual personality, not self-idealization. Psychol. Sci. 2010, 21, 372-374. [CrossRef]

61. Boyd, D.; Ellison, N.B. Social network sites: Definitions, history, and scholarship. J. Comput.-Mediat. Commun. 2008, 13, 210-230. [CrossRef]

62. Ellison, N.B.; Steinfield, C.; Lampe, C. The benefits of Facebook "friends:" Social capital and college students" use of online social network sites. J. Comput.-Mediat. Commun. 2007, 12, 1143-1168. [CrossRef]

63. Plant, R. Online communities. Technol. Soc. 2004, 26, 51-65. [CrossRef]

64. Parry, D.C.; Light, T.P. Fifty shades of complexity: Exploring technologically mediated leisure and women's sexuality. J. Leis. Res. 2014, 46, 38-57. [CrossRef]

65. Ember, C.R.; Ember, M.; Peregrine, N. Cross-Cultural Research. Handbook of Methods in Cultural Anthropology; Altamira Press: Plymouth, UK, 1998; pp. 647-687.

66. Seguino, S. The effects of structural change and economic liberalisation on gender wage differentials in South Korea and Taiwan. Camb. J. Econ. 2000, 24, 437-459. [CrossRef] 
67. Butler, Y.G. What level of English proficiency do elementary school teachers need to attain to teach EFL? Case studies from Korea, Taiwan, and Japan. Tesol. Q. 2004, 38, 245-278. [CrossRef]

68. Yang, W.S.; Yen, P.C. A comparative study of marital dissolution in East Asian societies: Gender attitudes and social expectations towards marriage in Taiwan, Korea and Japan. Asian J. Soc. Sci. 2011, 39, 751-775.

69. Bae, S.Y.; Yeo, M. The effect of the features of online community on leisure involvement and online community satisfaction: Focus on the mothers' online community, 'Song-pa-mom'. J. Tour. Leis. Res. 2016, 28, 5-25.

70. Yu, S.H.; Weng, C.; Huang, L.H. The study of information sharing in virtual parenting communities. J. Chaoyang Cult. Soc. 2014, 12, 97-120.

71. Bormann, J.E.; Smith, T.L.; Becker, S.; Gershwin, M.; Pada, L.; Grudzinski, A.H.; Nurmi, E.A. Efficacy of frequent Mantram repetition on stress, quality of life, and spiritual well-being in Veterans: A pilot study. J. Holist. Nurs. 2005, 23, 395-414. [CrossRef]

72. Wang, J.L.; Jackson, L.A.; Gaskin, J.; Wang, H.Z. The effects of Social Networking Site (SNS) use on college students' friendship and well-being. Comput. Hum. Behav. 2014, 37, 229-236. [CrossRef]

73. Alison Bryant, J.; Sanders-Jackson, A.; Smallwood, A.M. IMing, text messaging, and adolescent social networks. J. Comput.-Mediat. Commun. 2006, 11, 577-592. [CrossRef]

74. Mahan, J.E.; Seo, W.J.; Jordan, J.S.; Funk, D. Exploring the impact of social networking sites on running involvement, running behavior, and social life satisfaction. Sport. Manag. Rev. 2015, 18, 182-192. [CrossRef]

75. Coleman, D.; Iso-Ahola, S.E. Leisure and health: The role of social support and self-determination. J. Leis. Res. 1993, 25, 111-128. [CrossRef]

76. Felton, B.J.; Shinn, M. Social integration and social support: Moving "social support" beyond the individual level. J. Community Psychol. 1992, 20, 103-115. [CrossRef]

77. Boswell, D.M. Personal Crises and the Mobilization of the Social Network; Manchester University Press: Manchester, UK, 1969; pp. 254-296.

78. Lin, N.; Simeone, R.S.; Ensel, W.M.; Kuo, W. Social support, stressful life events, and illness: A model and empirical test. J. Health Soc. Behav. 1979, 20, 108-119. [CrossRef]

79. Yarcheski, A.; Mahon, N.E. The moderator-mediator role of social support in early adolescents. West. J. Nurs. Res. 1999, 21, 685-698. [CrossRef]

80. Cairney, J.; Boyle, M.; Offord, D.R.; Racine, Y. Stress, social support and depression in single and married mothers. Soc. Psychiatry Psychiatr. Epidemiol. 2003, 38, 442-449. [CrossRef]

81. Manning-Walsh, J. Social support as a mediator between symptom distress and quality of life in women with breast cancer. J. Obstet. Gynecol. Neonatal Nurs. 2005, 34, 482-493. [CrossRef]

82. McLanahan, S.S.; Wedemeyer, N.V.; Adelberg, T. Network structure, social support, and psychological well-being in the single-parent family. J. Marriage Fam. 1981, 43, 601-612. [CrossRef]

83. Kittinger, R.; Correia, C.J.; Irons, J.G. Relationship between Facebook use and problematic Internet use among college students. Cyberpsychol. Behav. Soc. Netw. 2012, 15, 324-327. [CrossRef] [PubMed]

84. Chang, Y.; Fine, M.A. Modeling parenting stress trajectories among low-income young mothers across the child's second and third years: Factors accounting for stability and change. J. Fam. Psychol. 2007, 21, 584-594. [CrossRef] [PubMed]

85. Deater-Deckard, K.; Scarr, S. Parenting stress among dual-earner mothers and fathers: Are there gender differences? J. Fam. Psychol. 1996, 10, 45-59. [CrossRef]

86. Bentler, P.M. Comparative fit indexes in structural models. Psychol. Bull. 1990, 107, 238-246. [CrossRef] [PubMed]

87. Tucker, L.R.; Lewis, C. A reliability coefficient for maximum likelihood factor analysis. Psychometrika 1973, 38, 1-10. [CrossRef]

88. Steiger, J.H. Structural model evaluation and modification: An interval estimation approach. Multivar. Behave Res. 1990, 25, 173-180. [CrossRef]

89. Bollen, K.A. A new incremental fit index for general structural equation models. Sociol. Method Res. 1989, 17, 303-316. [CrossRef]

90. Hu, L.T.; Bentler, P.M. Fit indices in covariance structure modeling: Sensitivity to underparameterized model misspecification. Psychol. Methods 1998, 3, 424-453. [CrossRef]

91. Hooper, D.; Coughlan, J.; Mullen, M.R. Evaluating Model Fit: A Synthesis of the Structural Equation Modelling Literature, Electron. J. Bus. Res. Methods 2008, 6, 53-60. 
92. Gaskin, J. “Group Comparison”, Stats Tools Package. Available online: http://statwiki.kolobkreations.com (accessed on 25 January 2016).

93. Burt, R.S. Interpretational confounding of unidimensional variables in structural equational modeling. Sociol. Method Res. 1976, 5, 3-52. [CrossRef]

94. Kline, R.B. Principles and Practice of Structural Equation Modeling, 2nd ed.; Guilford: New York, NY, USA, 2005.

95. Campbell, D.T.; Fiske, D.W. Convergent and discriminant validation by the multitrait-multimethod matrix. Psychol. Bull. 1959, 56, 81-105. [CrossRef] [PubMed]

96. Hair, J.F.; Anderson, R.E.; Babin, B.J.; Black, W.C. Multivariate Data Analysis: A Global Perspective, 7th ed.; Pearson: Hoboken, NJ, USA, 2010.

97. Bhattacherjee, A.; Sanford, C. Influence processes for information technology acceptance: An elaboration likelihood model. MIS Q. 2006, 30, 805-825. [CrossRef]

98. Henseler, J.; Ringle, C.M.; Sarstedt, M. A new criterion for assessing discriminant validity in variance-based structural equation modeling. J. Acad. Mark. Sci. 2015, 43, 115-135. [CrossRef]

99. Keil, M.; Tan, B.C.; Wei, K.K.; Saarinen, T.; Tuunainen, V.; Wassenaar, A. A cross-cultural study on escalation of commitment behavior in software projects. MIS Q. 2000, 24, 299-325. [CrossRef]

100. Sananes, N.; Guigue, V.; Kohler, M.; Bouffet, N.; Cancellier, M.; Hornecker, F.; Hunsinger, M.C.; Kohler, A.; Mager, C.; Neumann, M. Use of Z-scores to select a fetal biometric reference curve. Ultrasound Obstet. Gynecol. 2009, 34, 404-409. [CrossRef]

101. Cannon, W.B. The Wisdom of the Body; Norton: New York, NY, USA, 1932.

102. DeMeis, D.K.; Hock, E.; McBride, S.L. The balance of employment and motherhood: Longitudinal study of mothers' feelings about separation from their first-born infants. Dev. Psychol. 1986, 22, 627-632. [CrossRef]

103. Johnston, D.D.; Swanson, D.H. Cognitive acrobatics in the construction of worker-mother identity. Sex Roles 2007, 57, 447-459. [CrossRef]

104. Hays, S. The Cultural Contradictions of Motherhood; Yale University Press: Yale, CA, USA, 1996.

105. Tromholt, M.; Lundby, M.; Andsbjerg, K.; Wiking, M. The Facebook Experiment: Does Social Media Affect the Quality of Our Lives. Available online: http://www.happinessresearchinstitute.com/publications/4579836749 (accessed on 14 May 2017).

106. Mulcahy, C.M.; Parry, D.C.; Glover, T.D. Play-group politics: A critical social capital exploration of exclusion and conformity in mothers groups. Leis. Stud. 2010, 29, 3-27. [CrossRef]

107. Kahn, R.L.; Antonucci, T.C. Convoys over the life course: Attachment, roles, and social support. Life-Span Dev. Behav. 1980, 3, 253-286.

108. Kim, D.Y. Over $80 \%$ of the Working Mother Clients in Seoul Stated, "We Have Faced a Lack of Support at Work". Available online: http://www.munhwa.com/news/view.html?no=2017091401071427099001 (accessed on 14 May 2017).

Publisher's Note: MDPI stays neutral with regard to jurisdictional claims in published maps and institutional affiliations.

(C) 2020 by the authors. Licensee MDPI, Basel, Switzerland. This article is an open access article distributed under the terms and conditions of the Creative Commons Attribution (CC BY) license (http://creativecommons.org/licenses/by/4.0/). 